\title{
10 health stories that mattered: June 21-27
}

- British Columbians have the highest quality of life and residents of Nunavut the lowest, according to the interactive OECD Regional Well-Being website released by the Organisation for Economic Cooperation and Development. The scores, ranging from 0 to 10 in categories such as safety and health, are based on data from national statistics offices. Canadian scores in the health category are British Columbia (9.4), Alberta (8.1), Saskatchewan (6.7), Manitoba (6.7), Ontario (8.7), Quebec (8.6), New Brunswick (7.4), Nova Scotia (6.9), Prince Edward Island (6.7), Newfoundland and Labrador (5.9), Yukon (4.1), Northwest Territories (4.6), Nunavut (0).

- Guidelines for diagnosing and managing pediatric concussion were released by the Ontario Neurotrauma Foundation. They apply to youth aged 5-18. Most existing concussion guidelines target adults or athletes.

- GlaxoSmithKline (GSK) says it is "making progress" addressing concerns about quality control and manufacturing procedures at its vaccinemanufacturing facility in SainteFoy, Que., which produces influenza vaccines for the United States and Canada. On June 12, the US Food and Drug Administration sent a warning letter to GSK following an inspection that found deviations from current good manufacturing practice requirements, including a lack of procedures to prevent microbiological contamination of drug products.

- A molecule found in soil fungus from Nova Scotia is offering hope in the fight against antibiotic-resistant superbugs. Canadian researchers found that the molecule, aspergillomarasmine $\mathrm{A}$, restores the efficacy of an antibiotic in mice infected with a strain of resistant pneumonia.

- Some Canadian doctors are prescribing the antinausea drug ondansetron as an off-label treatment for severe morning sickness, even though it is suspected of sometimes causing serious adverse effects, according to a Toronto Star investigation. At least 20 Canadian cases of serious adverse effects, including infant deaths and babies born with heart defects and kidney problems, were discovered in the US Food and Drug Administration's Adverse Event Reporting System, reports the Star.

- Federal Health Minister Rona Ambrose launched the Advisory Panel on Healthcare Innovation to help "foster the kinds of innovation that improve the quality and costeffectiveness of our healthcare system." Dr. David Naylor, former president of the University of Toronto, will chair the panel.
- New restrictions may be required so that only Alberta Health Services can sponsor foreign physicians in Alberta, says the College of Physicians and Surgeons of Alberta. The college is concerned about the number of foreign physicians sponsored by private walk-in clinics (145 over the past two years).

- A resident of Saskatchewan has died from hantavirus pulmonary syndrome, a rare condition caused by infection with hantavirus from contact with the urine, feces or saliva of infected rodents. Since 1994, the province has reported only 27 cases of the syndrome. A third of the cases resulted in death.

- Ontario Premier Kathleen Wynne has appointed Dr. Eric Hoskins as the province's new Minister of Health. Hoskins, a family physician and humanitarian, cofounded the international charity War Child Canada with his wife, Dr. Samantha Nutt.

- The University of Toronto received a \$10-million donation to create an institute to study and improve First Nations health care. The donor, former neurosurgeon Dr. Michael Dan, is using some of the proceeds from the sale of the generic-drug company Novopharm Ltd., which was founded by his father. - Roger Collier, CMAJ

CMAJ 2014. DOI:10.1503/cmaj.109-4842 